\title{
\#24
}

\section{CUANDO PANDORA}

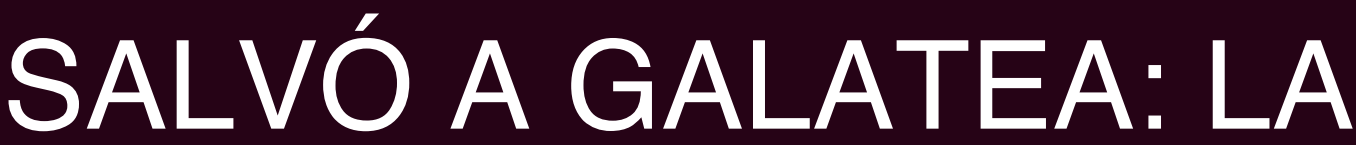

SORORIDAD COMO

RESPUESTA EN

"CASAS ROJAS», DE

NIEVES DELGADO

Manuel Santana Hernández

Universidad de Salamanca 


\section{$452^{6} \mathrm{~F}$}

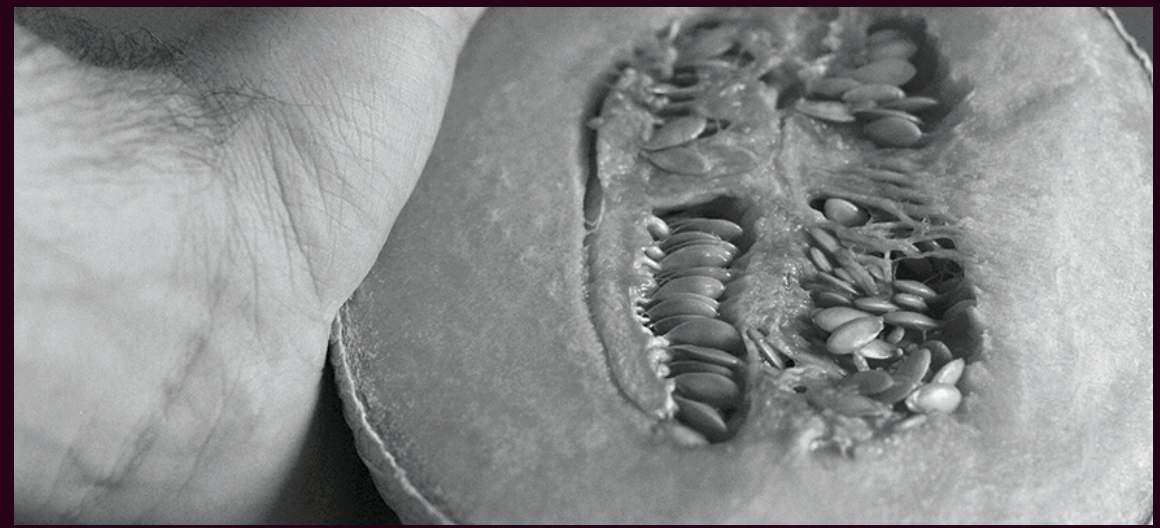

Resumen || Este artículo busca profundizar en cómo la ciencia ficción escrita por mujeres en el siglo XXI aborda problemas específicos de los sujetos femeninos, como los vínculos entre heteropatriarcado y capitalismo, la explotación sexual de las mujeres o la cosificación y deshumanización a la que se ven sometidas en una sociedad neoliberal. Para ello, analiza el relato "Casas Rojas» (2014) de la autora gallega Nieves Delgado. Concretamente, se centra en cómo la sororidad es una herramienta fundamental para luchar contra el heteropatriarcado y cómo el texto de Delgado dialoga con postulados teóricos de Andrea Dworkin, Teresa López-Pellisa, Isabel Clúa, Antonio Negri o Pilar Pedraza, entre otros.

Palabras clave || Ciencia ficción | Ginoides | Siglo XXI | Feminismo | Síndrome de Pandora

Abstract || This paper delves into how current science fiction written by Spanish women in the 21st century addresses specific issues regarding female subjects, such as the bonds between patriarchy and capitalism, sexual exploitation of women and the objectification and dehumanization women are exposed to in a neoliberal society. To accomplish my goal, the paper analyses the short story "Casas Rojas» (2014) by Galician author Nieves Delgado. In particular, it focuses on how sorority is a fundamental tool to fight against patriarchy and how Delgado's text can be read through theoretical postulates by Andrea Dworkin, Teresa López-Pellisa, Isabel Clúa, Antonio Negri and Pilar Pedraza, among others.

Keywords || Science Fiction | Gynoids | 21st century | Feminism | Pandora's syndrome

Resum || Aquest article busca aprofundir en com la ciència-ficció escrita per dones en el segle XXI aborda problemes especifics dels subjectes femenins, com ara els vincles entre heteropatriarcat $\mathrm{i}$ capitalisme, l'explotació sexual de les dones o la cosificació i deshumanització a la qual es veuen sotmeses en una societat neoliberal. Per a això, analitza el relat "Casas Rojas» (2014), de l'autora gallega Nieves Delgado. Concretament, es centra en com la sororitat és una eina fonamental per a lluitar contra l'heteropatriarcat $i$ com el text de Delgado dialoga amb postulats teòrics d'Andrea Dworkin, Teresa López-Pellisa, Isabel Clúa, Antonio Negri o Pilar Pedraza, entre d'altres.

Paraules clau || Ciència-ficció | Ginoides | Segle XXI | Feminisme | Síndrome de Pandora 


\section{Introducción ${ }^{1}$}

No cabe duda de que la ciencia ficción engloba un conjunto de textos que invitan a una reflexión crítica sobre algunos elementos del presente a través de su ficcionalización, lo cual relaciona el género con la filosofía y la política. También hay que tener en cuenta que las crisis sociopolíticas se viven como la pérdida del sentido que el mundo conocido solía tener (Ortega, 1982: 110), y su consecuencia más palpable es la proliferación de textos que no solo reflejan tal descontento, sino que también asumen un compromiso político activo y se muestran insumisos hacia el statu quo. En este sentido, resultan esclarecedores los trabajos de Moreno (2017, 2010: ii), donde se afirma que la literatura de ciencia ficción resulta, en realidad, la más apropiada para reflexionar acerca de nuestro tiempo, por cuanto su disección del presente, especialmente común en épocas de incertidumbre, lleva implícita un anhelo por hallar alternativas de pensar el mundo. Así, no es de extrañar que la crisis de 2008 haya favorecido la proliferación de textos ciencia ficcionales que, desde una perspectiva contestataria, ponen el acento en problemas como los abusos de la clase dominante, las contradicciones del neoliberalismo y su querencia hacia prácticas deshumanizantes, la relación de los seres humanos con las máquinas, los límites del concepto de «ser humano» o la opresión sobre determinadas minorías ${ }^{2}$, cuestión que ya ha sido mencionada:

No obstante, con el nuevo siglo ha llegado a la edad adulta un conjunto de lectores, escritores, editores y críticos que se criaron sin tantos prejuicios y con una mayor amplitud de miras. A muchos de ellos, la crisis de 2008 y el surgimiento de nuevos movimientos sociales les inspiraron historias y desarrollos más orientados hacia lo socio-político, que encontraron en lo proyectivo el espacio idóneo para hablar de viejos y nuevos mundos (SánchezTrigos, Clúa y Moreno, 2020: 20).

A este panorama cabe sumar dos cuestiones adicionales de absoluta importancia: el protagonismo de las tecnologías de la información en las representaciones artísticas propias de nuestro tiempo (Noguerol, 2008: 31) y la progresiva incursión de escritoras de ciencia ficción dentro de la literatura en español (Moreno, 2018: 181). Esta progresiva visibilización de mujeres dentro de un género tradicionalmente cultivado por hombres se ha traducido en nombres concretos como los de Susana Vallejo, Laura Fernández, Felicidad Martínez, Sofía Rhei, Cristina Jurado, Alicia Pérez Gil, Lola Robles, Elia Barceló, Samanta Schweblin, Liliana Colanzi, Rosa Montero o Nieves Delgado entre otras. Al mismo tiempo, para Moreno, su llegada ha conllevado la aparición de protagonistas femeninas y una ruptura con los estereotipos, roles y expectativas tradicionalmente asociados al género.

Este aumento en la visibilidad, aunque no implica que las mujeres hayan «conquistado» el género, sí ha permitido que se publiquen y editen numerosas novelas, obras de teatro y compilaciones de relatos escritos por mujeres. De hecho, Teresa López Pellisa (2019a: 75) ha definido este incremento como el "fenómeno Alucinadas», que ha otorgado a las autoras de ciencia ficción una visibilidad nunca vista. Ejemplos de ello son los textos que conforman las antologías de Alucinadas ${ }^{3}$ - publicadas anualmente durante cinco años(2014-2019), Las otras (2016), Insólitas (2019), Infiltradas (2019), los dos volúmenes de Poshumanas y distópicas (2020), novelas como Nuestro mundo muerto (2016), Bionautas (2018), Espejuelos para ver por dentro (2019), o las obras de teatro Evolución (2008) y Clonación (2011), entre otros muchos. En definitiva, se puede constatar que la ciencia ficción actual se encuentra atravesada transversalmente por la escritura de mujeres, que, según Moreno (2018: 182), presentan mayor acidez social y una visión más tendente a lo 
distópico. Al mismo tiempo, estas escrituras señalan las trabas que sufren las mujeres en la sociedad patriarcal del siglo XXI, los problemas asociados a los roles y las expectativas de género, la desigualdad estructural que sufren las mujeres, la deshumanización de los sujetos femeninos o las extensas relaciones entre patriarcado y capitalismo.

Dentro de este horizonte feminista, destaca la producción de la escritora gallega Nieves Delgado, autora de novelas como 36 (2017) o Uno (2018), y que señala en sus textos de ciencia ficción las grietas del capitalismo neoliberal, la opresión hacia las mujeres o los problemas del antropocentrismo patriarcal a través de figuras como androides o Inteligencias Artificiales. Para este artículo, he optado por trabajar su relato "Casas Rojas» (2014), con el objetivo de dar cuenta de los problemas hacia los que apunta: la prostitución y la trata de mujeres, su explotación sexual y la mercantilización de los cuerpos femeninos en la economía capitalista y las desigualdades de género fomentadas por el heteropatriarcado. Para lograr esta meta, he dividido el artículo en dos apartados. En el primero, repasaré las características fundamentales de la representación de las mujeres artificiales en la (ciencia) ficción, con el objetivo de sentar las bases teóricas para el análisis textual. En el segundo, analizaré «Casas Rojas» y lo relacionaré con otros textos de ciencia ficción feminista para entender de qué contexto viene Delgado, y con postulados teóricos de Judith Butler, Andrea Dworkin, Michel Foucault, Donna Haraway, Antonio Negri o Teresa López-Pellisa, entre otros muchos.

\section{Sumisas o rebeldes: la (po)ética patriarcal en la representación de las mujeres artificiales en la ciencia ficción}

Para comprender la forma en que se aborda la creación de mujeres artificiales, es necesario primero abordar la representación del sujeto femenino en la literatura, cuestión a la que la teoría feminista se ha dedicado fructíferamente durante el siglo XX. En este sentido, podría citarse la enorme contribución que han supuesto las reflexiones de Beauvoir (2010), y otras publicaciones que han seguido su estela, como las de Butler (2005), Friedan (2009) 4 o Cixous (1995), Almela, Leguen y Sanfilippo (2010) o Zavala y Díaz-Diocartez (2010). Todas estas aportaciones coinciden en señalar que, durante siglos, la representación de las mujeres en la cultura y la literatura las ha catalogado como objetos, opuestas al sujeto masculino universal, y las dividido en dos grupos: por un lado, las mujeres dóciles, entregadas a su esposo y al mal denominado «reposo del guerrero»; por otro, las contestatarias, las manipuladoras que arruinan a los hombres con su malicia y cuya única preocupación son ellas mismas. Las mujeres sumisas son propiedad de un hombre: o bien están casadas, o bien están a cargo de su padre ${ }^{5}$. Las mujeres rebeldes no son propiedad de nadie, pero ello no impide que sean objetos. Son mujeres públicas y en muchos casos ejercen la prostitución o son sexualmente explotadas. Esta forma de retratarlas ha acentuado las desigualdades de género y reforzado el poder patriarcal al poner delante estereotipos femeninos abiertamente misóginos.

Estas dos formas de tratamiento hunden sus raíces en la Antigüedad clásica, y de ahí han derivado a la cultura occidental. En este sentido, podrían darse varios ejemplos de la representación femenina en la literatura, pero conviene detenerse brevemente en dos: Penélope y las Amazonas. Ambas figuras aparecen en los textos de Homero, considerados comúnmente como el punto de origen de la literatura occidental. Adicionalmente, las amazonas han sido reivindicadas desde la teoría feminista como contraejemplos de feminidad, un ejercicio de protesta que Delgado también lleva a cabo en "Casas Rojas», tal y como detallaremos más adelante. Penélope constituye el ejemplo perfecto de 
la mujer sumisa, agradable, angelical y anfitriona. Madre de Telémaco, su destino es el silencio y su espacio el үuvaıкũv [gineceo]. Por el contrario, la mujer indómita, salvaje y rebelde queda representada en el mito de las Amazonas, en el que merece la pena detenerse por cuanto revela la función que ocupaban las mujeres en la Grecia clásica. Al igual que en el caso de Penélope, Homero ya menciona esta casta de mujeres guerreras, y el relato se transmitió hasta la obra de historiadores griegos posteriores como Apolodoro o Plutarco, para luego pasar a la cultura latina. Es importante tener en cuenta que, para los historiadores de la época, esta no era una mera narración mitológica ficcional, sino que contenía un componente de verdad (Millán, 2017: 43). La función principal del mito era contraponer el modelo amazónico, salvaje, exótico y bárbaro a la hermosa civilización griega, garante del «orden natural». Evidentemente, el carácter guerrero de las amazonas transgredía los roles de género, pero no desde una perspectiva feminista o crítica patriarcal. Era por tanto una transgresión indebida que debía evitarse. Las amazonas contraponían una colectividad casi animal frente a la individualidad del ciudadano griego, sujeto de derechos. Desde una perspectiva de género, su presencia se explica al menos en parte como un recurso narrativo que demoniza al sujeto femenino libre para justificar la necesidad de mantener la sociedad patriarcal. Al mismo tiempo, el mito ridiculiza la presencia política de las mujeres, las elimina del espacio público por cuanto sugiere que una mó $\lambda_{1 \zeta}$ [ciudad-Estado] administrada por ellas terminaría necesariamente en el colapso de la civilización. La expulsión del espacio público relega a la mujer al espacio privado, la sustrae de la vida en común y de la toma de decisiones y suprime la pluralidad de una sociedad. Es una práctica homogeneizadora que erradica la diferencia.

Las amazonas aparecen en varios episodios míticos, siempre bajo el papel de belicosas mujeres que atacan hostilmente el mundo de los héroes hombres (Millán, 2017: 48): Belerofonte lideró una campaña contra ellas, Teseo las combatió exitosamente a las puertas de Atenas, y Aquiles tuvo que hacerles frente en la guerra de Troya. En los relatos, las amazonas muestran capacidades tales como la una buena disposición física, la tenacidad para ejercer activamente su voluntad, la habilidad para el combate o el conocimiento del arte de la guerra, todas ellas aptitudes esenciales de la ápєтń o virtus ${ }^{6}$. Sin embargo, su representación casi monstruosa sugiere que la excelencia y la nobleza están reservadas para los sujetos masculinos y que hay un componente eugenésico que priva a las mujeres de alcanzar la grandeza. Así, el mito simboliza, a través de una horda monstruosa de mujeres guerreras, una

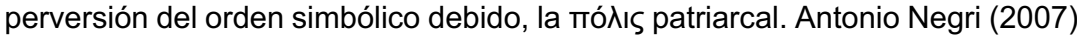
afirma que la principal función de los mitos en la Antigüedad es legitimar el statu quo defendiendo la pureza eugenésica de los gobernantes frente a la impureza del monstruo, una categoría cargada de contenido político. Así, dice: «solo aquel que es bueno y bello, eugenésicamente puro, está legitimado para el mando» (2007: 93). Platón, en su proyecto filosófico de La República, no se aleja demasiado de esta tesis cuando argumenta que solo los filósofos, conocedores de la idea de Bien $-\mathrm{y}$, por tanto, de la de armonía y de la de belleza- eran capaces de gobernar con verdadera justicia. En la Antigüedad, hablar del mando es hablar del ápxń, el principio rector que gobierna y está presente en todo lo demás ${ }^{7}$. Asociar el ápxń con el hombre equivale a que todos aquellos cuerpos que no sean masculinos serán inherentemente menos puros. De esta manera, la figura del monstruo amazónico es la de una mujer que está ocupando un lugar que no le corresponde porque está reservado para el hombre. Ello supone una desviación perversa del orden natural establecido, un alejamiento de la belleza propia de la norma, un ir contra natura. Por ello, solo cabe someter al monstruo a una biopolítica atroz, tal y como sucede con las amazonas: no son enemigas de módıs no por lo que hacen, sino por lo que 
son. En consecuencia, no cabe el diálogo con ellas. Su mera existencia compromete la del resto y deben ser combatidas hasta su aniquilación. Por ese motivo, ni son ni pueden llegar a ser sujetos de derechos. Millán (2017: 48), que ha estudiado esta cuestión, acierta al señalar que, en realidad, el mito amazónico en la Grecia clásica no deja de reflejar los miedos subconscientes de los varones, como exponentes del patriarcado.

Estas dos figuras sirven para demostrar lo que la crítica feminista ya ha señalado: que, en la retórica patriarcal, las mujeres solo pueden ser dom(in)adas o peligrosas. A esta misógina categorización han contribuido numerosísimos ejemplos: Medusa, cuyo pelo de serpientes simboliza la feminidad salvaje como un monstruo peligroso para los hombres que debe ser decapitado (López-Pellisa, 2019b: 76); Venus, nacida sin madre y cuya única identidad es la que su padre ha depositado sobre ella con su mirada omnisciente; Hipatia, cuyo asesinato no se explica sin el recelo patriarcal que despierta una mujer con poder; $u$ otras categorías observadas con desconfianza, como la bruja, la histérica o la cortesana. Así, no resulta disparatado asumir que esta dicotomía haya condicionado enormemente la creación de mujeres artificiales, tropo literario que constituye una de las primeras especulaciones sobre seres artificiales y es muy anterior al mito del Golem animado por la palabra de su creador o a Frankenstein o el moderno Prometeo (1818) ${ }^{8}$. Así lo señala Asimov (2012: 13) cuando apunta al hecho de que la primera mención a una mujer artificial se aprecia en La Ilíada, cuando Homero habla acerca de «un par de sirvientas [...] hechas de oro exactamente como muchachas vivientes, tienen juicio en sus cabezas». Sin embargo, el caso de las mujeres artificiales resulta particular dentro de la creación de seres porque sobre ellas se han volcado las fantasías, quimeras y miedos que inundan el imaginario cultural del heteropatriarcado. Pedraza señala con claridad cómo estas ilusiones han dado forma a las mujeres creadas:

Hay una fantasía flotando, tenaz, en nuestra cultura desde hace siglos: la de que el hombre creó a la mujer. Y otra aún más osada, que procede de ella: la de que el hombre produce criaturas femeninas más hermosas y mejores que las mujeres, con las que puede sustituir a éstas para lo bueno y para lo malo, para el amor sublime y para la paliza mortal (1998: 19).

Teniendo en cuenta que la literatura permite rastrear la imaginación política de cada época (Millán, 2017: 23), la representación tradicional de las mujeres artificiales dentro de la literatura occidental tiene uno de sus objetivos en perpetuar y reforzar los roles y las expectativas asociados al género. El hecho de que ya desde su primera manifestación se vincule a las mujeres artificiales con el concepto de servidumbre resulta revelador por dos cuestiones: en primer lugar, porque pone de manifiesto la concepción patriarcal que la Antigüedad tenía de los cuerpos femeninos; en segundo, porque evidencia que las formas de tratamiento que servían para la mujer se trasladaron desde muy pronto a los cuerpos femeninos artificiales, hecho que condicionará buena parte de las posteriores prospecciones ciencia ficcionales sobre esa cuestión.

Las doncellas de Hefesto no suponían una excepción en el tratamiento de los cuerpos femeninos artificiales. De hecho, había dos figuras específicas que reforzaban los estereotipos y roles de géneros, cuya influencia se ha transmitido a una gran cantidad de textos posteriores, lo cual ha perpetuado la existencia de un ambiente social masculino donde las mujeres carecían de espacio y voz propias. La primera figura se corresponde con el mito de Galatea, que habla de una mujer creada con el único objeto de satisfacer a su creador Pigmalión. Pilar Pedraza (1998: 41) sostiene que Pigmalión no se enamora de Galatea, sino de su propio genio creativo, en una suerte de narcisismo: Según Ovidio, Pigmalión esculpe a Galatea para que le haga compañía porque detesta 
los «vicios» de las mujeres de carne y hueso. Para Clúa (2005: 52), la posibilidad de crear artificialmente a una mujer sugiere la intención de manipularla y propone un juego erótico marcadamente desigual entre sujeto creador y objeto creado. Desde esta perspectiva, el mito entronca con la desigualdad estructural entre el hombre como sujeto activo y creador y el anhelo patriarcal de una mujer objeto, pasiva y dócil. En el mito, se resalta la belleza ${ }^{9}$ de Galatea y su buena disposición para con su creador, lo cual sugiere que las únicas mujeres hermosas y aceptables son las dominadas, que sirven sumisamente al varón y no (se) cuestionan su posición subalterna. El cuerpo artificial de Galatea supone el triunfo del simulacro al tiempo que dulcifica la figura de la mujer obediente. López-Pellisa (2019b: 39), por su parte, considera que el mito de Pigmalión y Galatea permite analizar los roles de género en los textos donde aparecen mujeres artificiales. Para ella, por tanto, Galatea también opera como una categoría transhistórica que encarna al ángel del hogar y es utilizada para referenciar a la mujer servil, cuya función no es otra que la satisfacción de su creador, innatamente superior.

La otra figura representativa de la visión clásica del sujeto femenino en la Antigüedad es igualmente conocida. Se trata de Pandora, que ya es mencionada en la Teogonía de Hesíodo. Si Galatea es la figura que representa el anhelo patriarcal de control, Pandora simboliza el miedo a una mujer perversa capaz de causar un gran daño. Según el mito, Pandora es otra mujer artificial, creada por Hefesto siguiendo las órdenes de Zeus. Hermes infundió en ella la malicia y la capacidad para el engaño. Pandora será la responsable de la ruina de Prometeo, y personifica a la femme fatale, aquella que ha de traer la desdicha por su indeseable disposición. Esta identificación hace que se consideren negativos el poder seductor de la mujer, su valentía y, en definitiva, la capacidad de actuar por sí misma sin estar sometida a ningún hombre (Millán, 2017: 52). El mito de Pandora relaciona a las mujeres con el caos y el pecado, de manera que encierra un aviso: señala a los hombres que se cuiden de las mujeres, que son traicioneras y ladinas. López-Pellisa (2015 y 2019b: 39) ha hablado del Síndrome de Pandora para reivindicar una nueva aproximación a los mitos de Pandora y Galatea como perspectiva analítica idónea para enfrentarse a aquellas obras de ciencia ficción que giran en torno a la creación de mujeres artificiales. Lo cierto es que Pandora resulta una figura apropiada para tratar textos protagonizados por mujeres que destruyen el mundo de servidumbre para el que han sido fabricadas, ya que a través de esta reinterpretación feminista el objetivo es analizar la insubordinación de las mujeres artificiales hacia el orden simbólico establecido, encarnado en Galatea. Ello permite que Pandora funcione como una categoría transhistórica que referencia a la mujer insumisa, a la muñeca que contesta y problematiza su propia sumisión y replica a la retórica patriarcal.

Ya sea porque se trata de mujeres dóciles de corte servicial o de féminas que traen irremediablemente la ruina al hombre como resultado de su malicia, lo cierto es que estas dos categorías, Pandora y Galatea, se pueden utilizar para clasificar las representaciones de buena parte de las mujeres artificiales en la ciencia ficción de los siglos $\mathrm{XIX}, \mathrm{XX}$ y $\mathrm{XXI}$, porque se trata de dos visiones contrapuestas profundamente asentadas dentro de la cultura occidental. En el siglo XIX, cuando emerge la ciencia ficción, la pulsión por la creación de mujeres artificiales se cubre con explicaciones científicas y técnicas de bioingeniería, a las que hay que sumar que la evolución que había sufrido la representación femenina desde la Antigüedad había resultado en la emergencia de dos estereotipos característicos del momento y antagónicos entre sí: el ángel del hogar, como ejemplo de mujer sumisa y madre abnegada que organiza el ámbito doméstico; y la femme fatale, la mujer que manipula y utiliza a los hombres para sus propios intereses egoístas. Así, esas dos 
representaciones, sumadas a todo un imaginario heteropatriarcal transmitido por la tradición, han favorecido que en buena parte de las obras de ciencia ficción donde se aborda la creación de mujeres artificiales se aprecie una notable misoginia y se reproduzcan los mitos de Pandora y Galatea como modelos de lo deseable y lo inapropiado, respectivamente. Olimpia en «El hombre de arena» (1817), de Hoffmann es un ejemplo, como también lo son Eva en La eva futura (1886) de Villiers de L'Isle-Adam, Alraune en La mandrágora (1911), de H.H. Ewers, Maria en Metrópolis (1927), de Fritz Lang o, ya de forma más contemporánea, Pris y Rachel en Blade Runner (1982), Número Seis en Battlestar Gallactica (2004), Ava en Ex Machina (2014), Joi en Blade Runner 2049 (2017), 36 en la novela 36 (2017), Arisa en Better than us (2018) o Reileen en Altered carbon (2018), por citar algunos.

En este punto, antes que llevar a cabo un recorrido por la historia de los cuerpos femeninos artificiales vistos en la ciencia ficción, quizá resulte más operativo ofrecer una serie de características comunes que suelen aparecer cuando se presentan mujeres creadas. En primer lugar, antes de su aparición el universo disfruta de una cierta armonía (López-Pellisa, 2012: 318). Las mujeres artificiales expulsan a la mujer real del espacio simbólico de la literatura y permiten establecer una retórica en la cual la dominación masculina patriarcal, o bien resulta incontestada y aceptada en su totalidad; o bien es respondida y ello convierte al hombre en la víctima. La mayoría de los rasgos de estas mujeres artificiales han sido perfectamente detallados por López-Pellisa:

\begin{abstract}
Generalmente, las mujeres artificiales han sido creadas por un varón solitario con conocimientos de ciencia o tecnología. Suelen tener una función de artefacto sexual, sirven para completar la simulación de una relación sentimental con su tecnopáter, se hace hincapié en su belleza (siempre similar a la de las estrellas de Hollywood), se resalta su eterna juventud (no envejecen como las mujeres orgánicas), se pone énfasis en su inmortalidad (aunque cuando son Pandoras, a veces se destruyen junto a sus creadores) y sus acompañantes varones suelen destacar la tranquilidad que les transmite su silencio (en algunas ocasiones el artefacto no posee la capacidad de hablar y esto se valora positivamente). Si estas mujeres facticias tienen cuerpo material, suelen ser voluptuosas y se destacan por las partes de su anatomía más sexualizadas [...] Por tanto, el imaginario tecnofeminino producido por varones en la literatura ( $\mathrm{y}$ el cine) de ciencia ficción continúa representando los mismos roles de género, creando artefactos como sustitutos de las mujeres reales en sus funciones de madres, esclavas sexuales y amas de casa, perpetuando la utopía patriarcal, solo que ahora recubierta de chips de silicio, inteligencia artificial y nano-tecnología (2019a: 86).
\end{abstract}

Ahora que se han expuesto brevemente qué rasgos tradicionales suelen aparecen en los textos de ciencia ficción en los que se trata la creación de mujeres artificiales, por fin es posible analizar «Casas Rojas» (2014), de Nieves Delgado. López Pellisa (2019a: 86) ha definido como «irónica» la lectura que debe hacerse del texto, ya que Delgado recurre a buena parte de estos rasgos para ofrecer un mensaje marcadamente feminista de sororidad frente a la explotación sexual, la cosificación de las mujeres o la connivencia entre patriarcado y las estructuras de poder capitalistas.

\title{
2. Todas somos Galatea: la sororidad entre mujeres orgánicas y artificiales como respuesta en «Casas Rojas»
}

El objetivo de este apartado del artículo es analizar el relato "Casas Rojas», relacionando los temas citados en el párrafo anterior con postulados teóricos y desde una perspectiva de género. Para ello, resulta fundamental en primer lugar contextualizar la producción de Delgado, definida por un palpable 
compromiso con la lucha de la mujer. El género ciencia ficcional $-\mathrm{y}$ la literatura - ha ofrecido una mayor visibilidad a los autores hombres, lo cual ha hecho que, en lo relativo a la representación de las mujeres, predomine una perspectiva heteropatriarcal. Pese a ello, no se puede afirmar que toda la representación de las mujeres, artificiales o no, haya sido siempre misógina en la ciencia ficción. Desde finales de los años 60 y principios de los 70 del siglo pasado, coincidiendo con el movimiento de liberación sexual de la mujer, han proliferado autoras de ciencia ficción como Ursula K. Le Guin, Joanna Russ u Octavia Butler, cuyo compromiso político con la lucha feminista es evidente. En este sentido, Melzer (2006: 4) advierte que «Feminists [...] recognize the political implications of the genre and increasingly employ science fiction narratives to explore social relations», y Lefanu (1989: 95) acierta cuando dice que la ciencia ficción es "feminism-friendly». Lo cierto es que la capacidad inherente del género para cuestionar las estructuras de poder y problematizar las injusticias sociales ha permitido que, a través de la literatura, se vehiculen reflexiones políticas y contraejemplos de feminidad escritos por una gran cantidad de autoras lo largo del siglo XX, lo cual ha facilitado una estrecha vinculación entre textos ciencia ficcionales y reflexiones políticas sobre las relaciones de poder existentes dentro del esquema heteropatriarcal.

Desde esta perspectiva, la ciencia ficción escrita por mujeres tiene un papel reivindicativo que reclama la superación, derribo o, cuando menos, el cuestionamiento del heteropatriarcado a través de personajes femeninos que revierten o cuestionan los roles y las expectativas tradicionalmente asociados al género mostrándose fuertes, inteligentes y combativas. Una de las reapropiaciones dentro de la ciencia ficción ha sido el mito amazónico ya comentado, y que ha tenido adaptaciones en clave feminista que resaltan como cualidad positiva su independencia de la mirada masculina. Ejemplos de ello son Motherlines (1978), de Suzy McKee Charnas, donde aparecen sociedades amazónicas de mujeres combatientes y resalta su fuerza, su dureza y versatilidad, para ofrecer una visión humana y no misógina del mito amazónico, o El hombre hembra (1978), novela de Joanna Russ donde los estereotipos asociados a la feminidad se desafían a través de la historia de cuatro mujeres que residen en universos diferentes pero que terminan interactuando y apoyándose las unas a las otras. Del mismo modo, otros ejemplos de personajes feministas que merece la pena mencionar son la teniente Ripley en Alien (1979), Sarah Connor en Terminator 2 (1992), la agente Scully en Expediente $X$ (1993) o Trinity en la saga Matrix (1999-2003). El denominador común de todos estos personajes que habilitan, a través de la literatura especulativa, una reflexión acerca de la imperante misoginia que han impedido que la mujer asuma posiciones de poder.

Este tipo de personajes señalan con su presencia que las características que se esperan del género femenino las han privado de tener espacios de protagonismo, y subvierten las expectativas de género desplegando habilidades, conocimientos o conductas típicamente asociadas a los hombres, como son la determinación, la valentía o conocimientos tecnológicos. Así, este tipo de representaciones conectan con el pensamiento feminista, tal y como han señalado autoras como Haraway (2016), Braidotti $(2000,2004)$ o Melzer (2006), quienes defienden que la ciencia ficción tiene un componente cultural innegable en la conformación de la subjetividad, y por ello asume la responsabilidad ética de crear modelos femeninos que sirvan como "caso práctico» de un marco sociopolítico no heteropatriarcal. De hecho, la propia Lefanu (1989: 9) señala que la ciencia ficción feminista posibilita cuestionar las estructuras de poder patriarcales. Este aspecto reivindicativo se halla presente en toda la producción de Nieves Delgado, y por ello la obra de la autora gallega se puede ligar a la de otras escritoras de ciencia ficción feminista que, tanto 
dentro como fuera del ámbito hispánico, han puesto el acento en la opresión que sufren las mujeres por el hecho de serlo.

Establecido el contexto, es momento de analizar el relato. Este se ambienta en un mundo futuro donde la empresa CorplA es capaz de fabricar ginoides y androides junior —con aspecto infantil- para que sean explotados sexualmente en prostíbulos o por clientes particulares, y a partir de ahí explora la breve relación entre Gabriel Sandler, presidente de CorplA; Noa, una funcionaria del gobierno enviada para supervisar la actividad de la empresa; y Silvana, la ginoide particular de Sandler. El texto se inicia presentando que la fabricación de ginoides con fines sexuales es un avance social: «Los sexbots han conseguido algo impensable: sacar a las mujeres de la calle. Mucha gente diría que eso es un avance social, créame» (Delgado, 2014: 297). Sin embargo, no se trata de un progreso por dos motivos: el primero, porque, aunque se pueda asumir que la existencia de sexbots implica que las mujeres orgánicas ya no han de ejercer la prostitución, lo que no se ha eliminado es la prostitución como práctica social generadora de desigualdad. De hecho, en todo caso se ha hecho más difícil de suprimir porque ahora opera dentro de la legalidad y de los mercados internacionales, lo cual implica un cierto grado de normalización $y$, más concretamente, que se trata de una práctica que genera impuestos, crea empleos - no los de las ginoides, sino los de sus programadores y vendedores - y se encuentra plenamente integrada dentro de las estructuras capitalistas. Así, el potencial liberador de la tecnología muta en potencial para someter a los sujetos.

De esta manera, se evidencian los vínculos entre patriarcado y capitalismo. Este último se encuentra atravesado transversalmente por enormes cantidades de trabajo precario - cuando no directamente esclavo-, uno de los cuales es, precisamente, la prostitución. Esta clase de trabajo genera y acentúa desigualdades, es realizado en condiciones infrahumanas y tiende a caer sobre mujeres en situaciones especialmente vulnerables. Mostrar la prostitución como un negocio lucrativo «perfectamente legal» (Delgado, 2014: 327) a través de Sandler, un hombre a caballo entre Pigmalión y el proxenetismo, refleja que la existencia de dicha práctica es lesiva para los derechos de las mujeres porque evidencia que sus cuerpos están sometidos a una mercantilización atroz. Andrea Dworkin (1989), que ha trabajado abundantemente la prostitución como práctica, considera que tiene que ver con la colonización del cuerpo femenino y supone fuerte ejercicio de violencia patriarcal. Así pues, la define como esclavitud sexual y sostiene que la libertad sexual es incompatible con la existencia de redes de prostitución, porque la lucha por la dignidad se encuentra enraizada en la pugna por el control del cuerpo. También apunta a que mientras exista la prostitución, la identidad femenina podrá ser reducida a la sexualidad (1989: 204), y ello perpetuará la cosificación de los sujetos femeninos. Dworkin advierte de que legalizar la prostitución mantiene la identidad femenina ligada a la esclavitud sexual y, por tanto, legitima la violación como práctica porque no se viola o profana un objeto cuando se usa, precisamente, para aquello para lo que está (Dworkin, 1989: 205). Prostitución y violación, por tanto, serían prácticas relacionadas cuyo denominador común es que permiten que la mujer cumpla su «función natural» dentro del heteropatriarcado: la de objeto sexual para el placer masculino. Esta percepción del cuerpo femenino entiende que el sexo es una mercancía, que las mujeres son las principales tenedoras de esa suerte de capital sexual y que los hombres tienen derecho a comprarlo por un precio determinado. Así, Dworkin (1989) defiende que pagar por sexo equivale a alquilar un servicio u objeto cuya propiedad no pertenece al arrendatario sino al arrendador. En el texto, esta visión del sexo como mercancía queda reflejada en las palabras del propio Sandler: «el sexo ha sido utilizado durante siglos como moneda de 
cambio» (Delgado, 2014: 324). De hecho, Sandler también afirma en múltiples ocasiones que la función de sus ginoides es proporcionar placer al hombre: «Nos interesa que los clientes queden satisfechos» (Delgado, 2014: 300); "Nuestros sexbots son la fantasía erótica de cualquiera» (2014: 317); «Nuestras sexbots están diseñadas para eso [...] Están a tu completo servicio, sin segundas intenciones. El sueño de cualquier hombre» (2014: 323).

La excusa que presenta Sandler cuando otros personajes le señalan lo deshumanizante que resultan estas prácticas es que las ginoides y los androides junior «no son personas en absoluto» (Delgado, 2014: 306), idea en la que insistirá en varias ocasiones: «son máquinas, exactamente igual que los demás productos» (Delgado, 2014: 305); «Siguen siendo máquinas» (2014: 311); "no se puede despersonalizar lo que no es una persona» (2014: 330). Sin embargo, la deshumanización de un determinado colectivo es un ejercicio de poder evidente, por cuanto politiza la definición de ser humano al incluir dentro de ella únicamente aquello que se considera aceptable —mientras que lo indeseable queda fuera-. Por este motivo, no son pocas las veces a lo largo de la historia que la deshumanización se ha utilizado como herramienta de opresión, con el objetivo de legitimar prácticas o actitudes abusivas hacia aquellos colectivos oprimidos. El propio Sandler admite que le incomoda que las ginoides sean humanizadas «no me gusta mucho que las llames "chicas", es una manera de humanizarlas» (Delgado, 2014: 312). Noa le confronta y pone de relieve que la despersonalización es, en realidad, un mecanismo que legitima el abuso: «El informe Gambrio demostró que uno de los mecanismos mentales de quienes recurren a la prostitución es despersonalizar completamente a las prostitutas» (Delgado, 2014: 329). Lo cierto es que, más allá de legitimar el abuso, la despersonalización anula la iniciativa del sujeto, porque los objetos carecen de voluntad. De esta manera, la deshumanización implica que las ginoides -y, por extensión, las mujeres - no tienen libertad sexual: son recursos para ser utilizados, herramientas para el placer de quienes quieran comprarlas. Al hilo del placer, Dworkin (1989: 206) considera que el goce sexual, comercializado como un entretenimiento simple y carente de ideología política, es síntoma de que existe una industria relacionada con el sexo perfectamente organizada.

La insistencia en afirmar que los sexbots no son personas deja como resultado que se las somete a una biopolítica atroz. Si el biopoder puede entenderse como el gobierno político de los cuerpos, es lógico pensar que el poder gestiona la vida, no solo decidiendo sobre la muerte sino también definiendo qué es la vida. Esta última aproximación es fundamental para entender el problema al que se enfrentan las mujeres artificiales en la ciencia ficción y, más concretamente, Silvana en el relato: poner en entredicho la vida de ser viviente de Silvana, transforma su existencia en una mera vida desnuda o zoé (Agamben, 2006): una existencia susceptible de ser sacrificada. Colanzi (2017: 17) apunta a que, de hecho, la dominación de cuerpos no humanos es fundamental para el desarrollo del sistema capitalista en Occidente, porque permite catalogarlos como un mero conjunto de piezas dóciles, maleables y dispuestas para su correcta utilización dentro de instancias productivas. Colanzi (2017: 18) también afirma que la ciencia ficción del siglo XXI tiene la tendencia a construir al monstruo al margen de la comunidad humana y de convertirlo en una vida desechable que no merece protección.

Delgado parte de esta premisa, pero la subvierte al conferir valor y dignidad a la existencia de Silvana $-\mathrm{y}$, de nuevo por extensión, a la vida de todas las ginoides y mujeres-. Es aquí cuando el relato avanza. Noa, fingiendo que forma parte de su trabajo de supervisión, pide a Sandler entrevistarse con Silvana, su ginoide personal. De la reunión entre ambas solo se muestra una 
parte, en la que Noa pregunta por el estado de la Ginoide: «Dime otra cosa; cuando tienes sexo con Gabriel, ¿cómo te sientes?» (Delgado, 2014: 335). En la parte del encuentro que Delgado omite, Noa reprograma a Silvana para permitirle librarse de su servidumbre, pero el lector no averigua esta información hasta prácticamente el final del relato. El motivo de su conducta se intuye en la siguiente escena, cuando Sandler le pregunta a Noa cómo ha ido la reunión y ella le informa de que la ginoide parece más que una simple máquina: «a mí me parece que Silvana es mucho más sensitiva de lo que tú te crees» (2014: 336). En esa misma escena, Noa subraya que Silvana no tiene deseo de tener relaciones sexuales con él: «Lo que creo es que Silvana no disfruta del sexo contigo» (2014: 337). Esta cuestión no debe pasar inadvertida porque es el motor del comportamiento de Noa y resulta clave para el desenlace: Noa considera a Silvana un sujeto deseante, y por tanto la ve como una mujer artificial explotada sexualmente y sin capacidad de liberarse debido a su programación: "creo que tú no puedes elegir no hacer lo que haces. ¿Puedes abrir esa puerta, salir por ella y no volver nunca más?» (Delgado, 2014: 334). Tanto si la única diferencia entre Noa y Silvana es una cuestión de bioingeniería como si no, la actuación de la primera supone la liberación de la segunda.

Si Silvana es una esclava sexual, necesariamente Sandler es su abusador. Por tanto, Noa se propone arruinar su empresa y liberar no solo a Silvana, sino a todas las ginoides sexualmente explotadas y privadas de la capacidad para liberarse. Ese matiz en apariencia irrelevante es de hecho crucial, porque sugiere que Noa no sitúa el problema en el abuso de Sandler hacia Silvana, sino en la posibilidad de abusar de cualquier ginoide sencillamente programándola para que no pueda ser libre. Así pues, Noa conduce a Sandler a una "zona neutra», un espacio que el texto define como un lugar donde "los robots, liberados de su programación de servidumbre, interaccionaban entre sí y con los humanos» (Delgado, 2014: 339). Allí advierte a Sandler de que «aquí las ginoides no están a tu servicio. Puede que tengas suerte y alguna se decida a tener sexo contigo» (Delgado, 2014: 344). El objetivo de esta visita es mostrar a Sandler que las ginoides tienen la capacidad de desear.

El relato alcanza su desenlace cuando el Sandler vuelve a recurrir a Silvana para satisfacer su deseo sexual y esta se defiende de él. Noa acude a visitarle al hospital y le aclara que ella modificó a Silvana y que, si la hubiese liberado, habría podido evitar el incidente: «hubiera sido suficiente con liberarla, pero no lo hiciste. Me preguntó por qué... ¿posesión, tal vez?» (Delgado, 2014: 350). Más aún, completa su confesión reconociendo que su conducta es una respuesta ante la falta de ética de CorplA:

«Tiene que ver con tu empresa, con lo que hacéis [...] Ya viste lo que son los robots libres [...] ¿de verdad crees que deben seguir siendo esclavos? [...] Un robot que desee tener sexo, y no solo estar disponible para su amo [...] necesita libertad para desarrollarse y nosotros queremos dársela» (Delgado, 2014: 351).

En el apartado anterior, se explicó que el imaginario cultural, en el que la literatura ocupa un lugar predominante, clasificaba a las mujeres en dos categorías: sumisas y rebeldes. En la ciencia ficción, estas dos figuras se simbolizan a través de Galatea y Pandora (López-Pellisa, 2019a). Ahora bien, la importancia de "Casas Rojas» como reivindicación feminista es que Delgado apela a estas dos categorías para mandar un fuerte mensaje de sororidad frente al abuso sexual. Silvana, mujer creada con el único propósito de «atender al señor Sandler en sus necesidades privadas; estar siempre disponible para él» (Delgado, 2014: 333), simboliza a Galatea. Sandler, como ya se indicó anteriormente, es una suerte de Pigmalión. De hecho, la 
descripción más certera de Silvana la realiza el propio Sandler, lo cual es indicativo de que la ginoide carece de voz propia y de libertad propias:

Con ella puedo tener todo lo que quiera sin dar nada a cambio. No tengo que negociar, no tengo que pedir permiso, no tengo que seguir las reglas sociales. Ella nunca me pedirá respeto, cariño o amistad. Es sexo puro (Delgado, 2014: 326).

Por su parte, Noa no es definida a través de las palabras de un hombre, sino de las suyas propias y, especialmente, de sus acciones. Su conducta quiebra CorplA: «Siento ser yo quien te diga esto, pero la cotización de CorplA en Bolsa está cayendo en picado y la gente se deshace de sus sexbots en masa. Tu empresa está acabada, Gabriel»(Delgado, 2014: 353). Su capacidad para rebelarse ante Sandler y acabar con su empresa hacen que adopte la categoría de Pandora.

Lo interesante del relato es que, si se analiza atendiendo al Síndrome de Pandora (López-Pellisa, 2015), parece evidente que Delgado actualiza el mito pandórico para reapropiárselo desde el feminismo: en esta ocasión, la rebelión de Pandora no se presenta como algo negativo, sino como un acto de rebelión cuyo objetivo es conseguir la necesaria liberación de la mujer de una estructura, como es la prostitución, profundamente patriarcal. Noa entiende que Silvana las representa a todas, puesto que, como señala López-Pellisa (2019a: 86), es la simulación de ciertos comportamientos y la representación de ciertas actitudes lo que crea, genera y consolida lo Real. Así, el texto postula que la existencia de mujeres artificiales como Silvana, sometidas a prácticas deshumanizantes y privadas de libertad, resulta irreconciliable con la liberación de la mujer. Una sexualidad basada en la propiedad de los cuerpos ajenos es, evidentemente, generadora de desigualdades sociales enormes.

\section{Conclusiones}

En este punto, parece claro que Nieves Delgado se ha apropiado del Síndrome de Pandora para mandar un mensaje feminista de sororidad y apoyo ante los abusos sexuales, a través de un relato corto de ciencia ficción. Este artículo ha intentado mostrar algo de luz sobre esa cuestión, pero quedan todavía muchos interrogantes por contestar, que requeririan una investigación más detallada: ¿es posible encontrar la tesis abolicionista en otros textos de la autora? ¿y en otras autoras? ¿Qué posturas hay respecto al trabajo sexual en la nómina de autoras que actualmente hay en ciencia ficción? ¿Puede verse una reapropiación del monstruo con finalidad política, como postula Antonio Negri, como una herramienta narrativa en la ciencia ficción escrita por mujeres en el siglo $\mathrm{XXI}$ ? $\mathrm{Y}$, si es así, ¿qué otros monstruos están estas autoras reivindicando? ¿Cabría hablar de un bestiario poshumano, biogenético, de nuevo cuño? Y si es así ¿qué figuras del mismo estarían escritas por mujeres y qué papel ocupan las autoras como (re)creadoras de monstruos? ¿lo hacen en favor del feminismo?

Lo que parece cierto es que en un momento como el actual, cuando la lucha de la mujer comienza a adquirir centralidad dentro del panorama político y social y donde fenómenos como el movimiento \#MeToo todavía no han dicho la última palabra, la (ciencia) ficción va a tener un peso enorme para (de)construir las estructuras de las democracias capitalistas neoliberales que, a pesar de las injusticias que determinados sectores sufren a diario, todavía se presentan como la forma más perfecta de gobierno. Ante esta situación, parece que, al menos durante un tiempo, los textos de ciencia ficción todavía tienen un 
arduo trabajo por delante como elementos privilegiados de transformación social, política y cultural y como prospección hacia un mundo menos desigual. Por otro lado, las grietas de nuestro presente abiertamente confuso, líquido y heteropatriarcal, a pesar de ser todavía muy numerosas, se van cerrando gradualmente, lo cual significa que, aunque sea poco a poco, la sociedad avanza.

\section{Notas}

${ }^{1}$ Este artículo se ha realizado en el contexto del proyecto «Exocanónicos: márgenes y descentramiento en la literatura en español del siglo XXI» (PID2019-104957GA-I00), financiado por el Ministerio de Ciencia, Innovación y Universidades.

${ }^{2}$ El auge de obras de este género se debe también a la aceptación generalizada de este tipo de obras, lo cual ha conducido a que editoriales, productoras de cine y cadenas de televisión se beneficien de un incipiente nicho de mercado apostando por contenidos ciencia ficcionales.

${ }^{3}$ En 2019, el proyecto Alucinadas dejó de publicar convocatorias, al considerar que la necesidad que lo había motivado inicialmente había quedado cubierta. Ello prueba el aumento de visibilidad de las autoras de ciencia ficción.

${ }^{4}$ Aunque la edición de Beauvoir citada en este artículo es de 2010, su trabajo fue publicado inicialmente en 1949. Lo mismo sucede con Butler y Friedan: sus trabajos fueron publicados en 1956 y 1963, respectivamente, pero las ediciones trabajadas son las de 2007 y 2009.

${ }^{5}$ En muchos casos, la relación entre padre e hija resulta incestuosa por cuanto son pareja sexual.

${ }^{6}$ ápetń: virtud (que legitima para el mando político).

7 ápxń: fundamento, principio. Hace referencia al elemento del que deriva toda la realidad material.

${ }^{8}$ Obra considerada si no el nacimiento del género al menos un claro antecedente, y donde Mary Shelley especula con las posibilidades del galvanismo

${ }^{9}$ Dentro de la estudiada y controvertida relación entre ética y estética, uno de los axiomas fundamentales que atraviesan el arte grecolatino clásico es que lo bello es bueno, mientras que lo feo es lo malo. Esta idea se representaba con el sustantivo ка入окаүаӨía, que designaba conjuntamente una belleza exterior y una pureza de espíritu. Es por ello que cuando se acentúa la belleza de Galatea, también se está señalando su buena disposición ética y, más concretamente, que es bueno que sea sumisa. 


\section{Bibliografía citada}

AGAMBEN, G. (2006): Lo abierto: el hombre y el animal, Buenos Aires: Adriana Hidalgo.

ALMELA, M.; LEGUEN, B.; y SANFILIPPO, M. (2010): Universos femeninos en la literatura actual, Madrid: Uned.

AMORÓS, C. (2007): Teoría feminista: de la ilustración a la globalización, Madrid: Minerva.

BEAUVOIR, S. (2010): El segundo sexo, Madrid: Cátedra.

BRAIDOTTI, R. (2000): Sujetos nómadas: corporización y diferencia sexual en la teoría feminista contemporánea, Buenos Aires: Paidós.

BRAIDOTTI, R. (2004): Feminismo, diferencia sexual y subjetividad nómade, Barcelona: Gedisa.

BUTLER, J. (2007): El género en disputa: el feminismo y la subversión de la identidad, Barcelona: Paidós.

CIXOUS, H. (1995): La risa de la Medusa: ensayos sobre la escritura, Barcelona: Anthropos.

CLÚA, I. (2005): «Cuando Galatea es Pigmalion»: la artificialización de la identidad femenina en el fin-de-siecle», Asparkia: investigació feminista, núm. 16, pp 49-70.

COLANZI, L. (2017): Of Animals, Monsters, and Cyborgs. Alternative Bodies in Latin American Fiction (1961-2012). Tesis doctoral sin publicar. Universidad de Cornell, EE. UU.

DELGADO, N. (2014): «Casas Rojas» en Jurado, C. (ed.) Alucinadas. Ebook, 290-356. <https://bit.ly/38W3e2F> [29/07/2020]

DWORKIN, A. (1989): Pornography. Men possesing women, New York: Penguin.

FRIEDAN, B. (2009): La mística de la feminidad, Madrid: Cátedra.

HARAWAY, D. (2016): Manifiesto para cyborgs: ciencia, tecnología y feminismo socialista a finales del siglo XX, Barcelona y Mar del Plata: Puente aéreo.

LEFANU, S. (1989): Women and Science Fiction, Indiana: Indiana University Press.

LÓPEZ-PELLISA, T. (2012): «El síndrome de Pandora: máquinas de amar, de Pilar Pedraza» en Vilches de Frutos, F., Imágenes femeninas en la literatura y las artes escénicas (siglos $X X-X X I$ ), Philadelphia: Society of Spanish and Spanish-American Studies, pp 315-335.

LÓPEZ-PELLISA, T. (2015): Patologías de la realidad virtual: cibercultura y ciencia ficción, Madrid: Fondo de Cultura Económica.

LÓPEZ-PELLISA, T (2019a): «Alucinadas I y II: el retorno de Metis y las escritoras españolas de ciencia ficción», Hélice: reflexiones críticas sobre ficción especulativa, volumen $\mathrm{V}$, núm., 75-97.

LÓPEZ-PELLISA, T. (2019b): «¿Sueña Torrente Ballester con mujeres eléctricas? El síndrome de Pandora en Quizás nos lleve el viento al infinito», La tabla redonda: anuario de estudios torrentinos, núm. 17, 37-62.

MILLÁN, S. (2017): Reinos de amazonas en la literatura española de la Edad Media y los Siglos de Oro: arquetipos, género y alteridad. Tesis doctoral sin publicar. Universidad de Valencia, España.

MELZER, P. (2006): Alien Constructions: Science Fiction and Feminist Thought, Texas: University of Texas Press.

MORENO, F. A. (2010): Teoria de la Literatura de ciencia ficción: poética y retórica de lo prospectivo, Vitoria: Portal.

MORENO, F. A. (2017): Estudio del futuro: didáctica de la ciencia ficción, Ciudad de México: Bonilla Artigas Editores. 
MORENO, F. A. (2018): «Narrativa 2000-2015» en López-Pellisa, T. (ed.), Historia de la ciencia ficción en la cultura española, Madrid: IberoamericanaVervuert, 177-195.

NEGRI, A. (2007): «El monstruo político. Vida desnuda y violencia» en Giordi, G. (comp.), Ensayos sobre biopolítica. Excesos de vida, Buenos Aires: Paidós, 93-141.

NOGUEROL, F. (2008): «Narrar sin fronteras» en Montoya, J. Entre lo local y lo global: la narrativa latinoamericana en el cambio de siglo, Madrid: Iberoamericana-Vervuert, 19-35.

ORTEGA, J. (1982): En torno a Galileo, Madrid: Alianza.

PEDRAZA, P. (1998): Máquinas de amar: secretos del cuerpo artificial, Madrid: Valdemar.

SÁNCHEZ-TRIGÓS, R.; CLÚA, I.; y MORENO, F.A. (2020): «La literatura proyectiva española desde la crisis: una visión de conjunto», Quimera: revista de Literatura, núm. 439-440, 20-25.

ZAVALA, I.; y DÍAZ-DIOCARETZ, M. (1993): Breve historia feminista de la literatura española (en lengua castellana). Madrid: Anthropos. 